\title{
Effects of abdominal vagotomy on serum LH concentrations in female rats
}

\author{
L. G. Allen*, I. E. Lawrence, Jr, H. W. Burden and C. A. Hodson† \\ Departments of Anatomy and $\dagger$ Obstetrics and Gynecology, East Carolina University School of Medicine, \\ Greenville, NC 27834, U.S.A.
}

\begin{abstract}
Summary. Vagotomy on the morning of pro-oestrus did not prevent the pro-oestrous LH surge and rats became oestrous on the following day. However, vagotomized rats then exhibited a period of acyclicity which lasted for $20.4 \pm 1 \cdot 3$ (s.e.m.) days. Food intake and body weight also declined after vagotomy. During the first week after vagotomy, afternoon LH surges generally did not occur, a pattern which was similar in animals pair fed with vagotomized rats. However, pair-fed rats showed oestrous cycles while vagotomized rats were acyclic. At 7 days after vagotomy, LH surges were induced by oestradiol benzoate and progesterone treatment of ovariectomized rats. Vagotomy suppressed the post-ovariectomy increase in serum LH at 7 and 21 days after surgery. These results, combined with those of other studies, suggest impairment of LH release in vagotomized rats.
\end{abstract}

\section{Introduction}

Ovarian innervation has been demonstrated in a number of species (Jacobowitz \& Wallach, 1967; Burden, 1972; Unsicker, 1974; Lawrence \& Burden, 1976; Stefenson, Owman, Sjoberg, Sporrong \& Walles, 1981). Most studies of ovarian innervation have described the pattern of adrenergic nerves within the ovary. After injection into the rat ovary, horseradish peroxidase was localized in both inferior ganglia of the vagus nerve as well as in ipsilateral dorsal root ganglia from levels T10 through $\mathrm{Ll}$, thus showing a vagal contribution to the sensory innervation of the rat ovary (Burden, Leonard, Smith \& Lawrence, 1983a).

The possible role of ovarian vagal sensory innervation has been assessed by observing reproductive function after subdiaphragmatic vagotomy. Studies with rats have shown that vagotomy alters oestrous cyclicity (Burden, Lawrence, Louis \& Hodson, 1981), blocks induction of pseudopregnancy (Burden et al., 1981), prevents compensatory ovarian hypertrophy (Burden \& Lawrence, 1977), delays onset of puberty (Ojeda, Smith-White, Aguado, Advis \& Andersen, 1983), and increases fetal resorption during pregnancy (Lawrence, Burden \& Louis, 1978). These effects of vagotomy on reproductive function may be due to direct effects on the ovary (Sanders \& Peppler, 1982; Ojeda et al., 1983) or to decreased gonadotrophin release (Burden \& Lawrence, 1977; Lawrence et al., 1978; Leonard et al., 1984). The purpose of the present study was to examine further the effects of vagotomy on luteinizing hormone (LH) release in female rats.

\section{Materials and Methods}

Animals. Female Sprague-Dawley rats (Animal Resources Center, East Carolina University School of Medicine) were housed singly in wire-bottomed cages and were maintained in a photoperiod of $14 \mathrm{~h}$ light (05:00-19:00 h) per $24 \mathrm{~h}$. Rat food (Wayne lab blox, Chicago, IL) and

* Present address: Department of Obstetrics and Gynecology, University of Florida College of Medicine, P.O. Box J-294 JHMHC, Gainesville, FL 32610, U.S.A. 
water were available ad libitum unless otherwise indicated. In studies in which oestrous cycles were monitored, only rats with regular 4-day oestrous cycles were used.

Surgery. All surgery was performed under ether anaesthesia. In performing subdiaphragmatic vagotomy, a midventral incision was made caudal to the xiphoid process and along the linea alba. The liver was gently reflected cranially and the stomach exposed. To reach the oesophagus, the gastrohepatic ligament was cut. The oesophagus was gently retracted to the animal's left, exposing the posterior vagal trunk. The posterior vagal trunk was then isolated with a Tyrell hook and severed. On the anterior surface of the oesophagus, the anterior vagal trunk was located and severed. Sham vagotomy consisted of exposing and manipulating the oesophagus to view the anterior and posterior vagal trunks. After surgery, the abdominal musculature was sutured and the skin was closed with wound clips. Antibiotic (20000-30000 i.u. penicillin) was administered i.m. At autopsy, those rats with an enlarged, distended stomach were considered to be vagotomized.

Experiment I. Between $09: 00$ and $12: 00 \mathrm{~h}$ on the day of pro-oestrus, rats were subjected to vagotomy $(N=15)$ or sham vagotomy $(N=15)$. Between $15: 30$ and $16: 00 \mathrm{~h}$ on the same day, $0 \cdot 3-$ $0.5 \mathrm{ml}$ blood was collected by orbital sinus puncture under ether anaesthesia. Blood samples were stored overnight at $4^{\circ} \mathrm{C}$. Serum was separated and stored $\left(-20^{\circ} \mathrm{C}\right)$ until assayed. After surgery, oestrous patterns (as determined by vaginal lavage) and body weights of 10 rats in each group were monitored daily. Serum LH was measured by radioimmunoassay (RIA).

Experiment II. On the morning of pro-oestrus, rats were subjected to vagotomy $(\mathrm{N}=10)$ or sham vagotomy $(\mathbf{N}=9)$. Due to reported decreases in food intake after vagotomy (Mordes, Herrera \& Silen, 1977; Mordes, el Lozy, Herrera \& Silen, 1979), females in a third group $(\mathbf{N}=7)$ were subjected to sham vagotomy and were pair fed with the vagotomized rats. For the pair feeding procedure, individual sham-vagotomized rats were matched with individual vagotomized rats and given the amount of food that the vagotomized rats consumed on each particular day of the study. For determination of food intake, a known amount of diet was placed in the food hopper each morning. On the following morning, remaining food and spilled food were weighed and food intake was calculated. Water was available ad libitum. On the afternoon of pro-oestrus, and for the 6 subsequent days, rats were bled daily by orbital sinus puncture at 16:00 $\mathrm{h}$. Rats were weighed and oestrous cycles were monitored daily. At 7 days after surgery, rats were decapitated (between 09:00 and 12:00 h) and trunk blood was collected. Ovaries and uteri were cleaned and weighed. Serum LH was measured in duplicate $50 \mu \mathrm{l}$ samples.

Experiment III. Female rats were ovariectomized 4 weeks before use in the study and were then vagotomized $(\mathrm{N}=11)$ or sham vagotomized $(\mathrm{N}=15)$ on Day 0. On Day 5 , all rats were treated with $5 \mu$ g oestradiol benzoate s.c. (in $0.1 \mathrm{ml}$ corn oil). At 10:00 h on Day 7, rats were bled by orbital sinus puncture and given $1.5 \mathrm{mg}$ progesterone s.c. (in $0.1 \mathrm{ml}$ corn oil; Kalra, Kalra, Krulich, Fawcett \& McCann, 1972). The rats were bled again at 16:00 h and decapitated at 18:00 h. Trunk blood was collected and serum LH was measured by RIA.

Experiment $I V$. Female rats having at least 2 consecutive 4-day oestrous cycles were used. On the morning of dioestrus, rats were bled by orbital sinus puncture and then underwent vagotomy or sham vagotomy followed by bilateral ovariectomy. Animals were bled by orbital sinus puncture at $1,4,7,14,21$ and 28 days after surgery. Serum LH was measured by RIA.

$L H$ radioimmunoassay. Serum $\mathrm{LH}$ concentrations were measured using radioimmunoassay kits supplied by the Hormone Distribution Program of the National Institutes of Health (Bethesda, MD, U.S.A.). Assays were performed by the double-antibody method using the instructions enclosed with the kits. LH antibody was NIH anti-rat-LH-S4. LH standard was NIH-RP1. Serum samples from each experiment were run within the same assay. The mean intra-assay coefficient of variation from 6 replicates of serum from ovariectomized rats (mean $\mathrm{LH}=456 \mathrm{ng} / \mathrm{ml}$ ) was $4.46 \%$ and sensitivity for the assay was $1.25 \mathrm{ng} /$ tube. 
Statistics. Statistical analysis of differences between two means was done by $t$ test. Analysis of differences involving more than two means was done by one-way analysis of variance and StudentNewman-Keuls multiple comparisons test.

\section{Results}

Experiment I: effects of vagotomy on LH concentrations on the afternoon of pro-oestrus and oestrous cyclicity

After surgery on the morning of pro-oestrus, rats in both experimental groups had elevated levels of $\mathrm{LH}$ at 15:30-16:00 h. Mean \pm s.e.m. concentrations were $735 \pm 92 \mathrm{ng} / \mathrm{ml}(\mathrm{N}=15)$ for the vagotomy group and $761 \pm 99 \mathrm{ng} / \mathrm{ml}(\mathrm{N}=15)$ for the sham-vagotomy group. On the following day, all rats became oestrous (Text-fig. 1). All sham-operated rats continued to exhibit oestrous cyclicity after surgery. However, the vagotomized rats entered a prolonged period of acyclicity in which the predominant vaginal smear pattern was initially heavily leucocytic. Vagotomized rats lost weight after surgery (Text-fig. 2). Body weights of vagotomized rats began to increase 10 days-2 weeks after surgery, but generally remained lower than body weights of sham-vagotomized rats.

Oestrous cycles eventually returned in vagotomized rats at $20.4 \pm 1.3$ (s.e.m.) days after surgery and the cycles appeared to be of normal length (4-5 days) (Text-fig. 1).

Experiment II : effect of vagotomy or pair feeding on daily afternoon $L H$ concentrations and oestrous patterns

As in Exp. I, vagotomy on the morning of pro-oestrus did not block the afternoon LH surge or prevent rats from becoming oestrous on the following day (Text-fig. 3). However, during the 7 days after surgery, 9 of 10 vagotomized rats were acyclic while all sham-vagotomized rats maintained

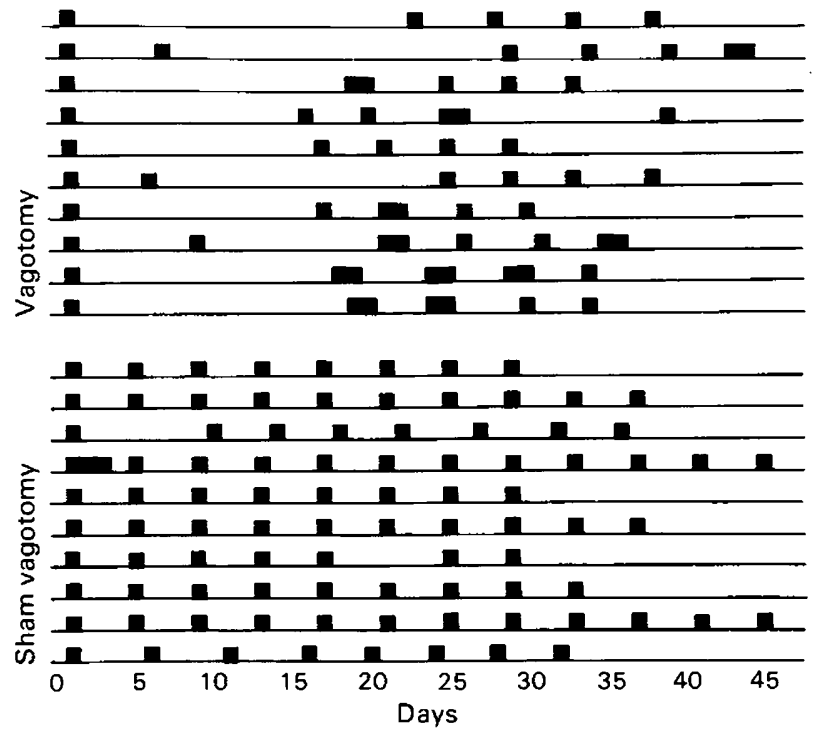

Text-fig. 1. Oestrous patterns of vagotomized $(N=10)$ and sham-vagotomized $(N=10)$ rats. Surgery was performed on the morning of pro-oestrus (Day 0). Each symbol represents the observation of a cornified vaginal smear. Monitoring of oestrous cycles was terminated 30-45 days after surgery. 


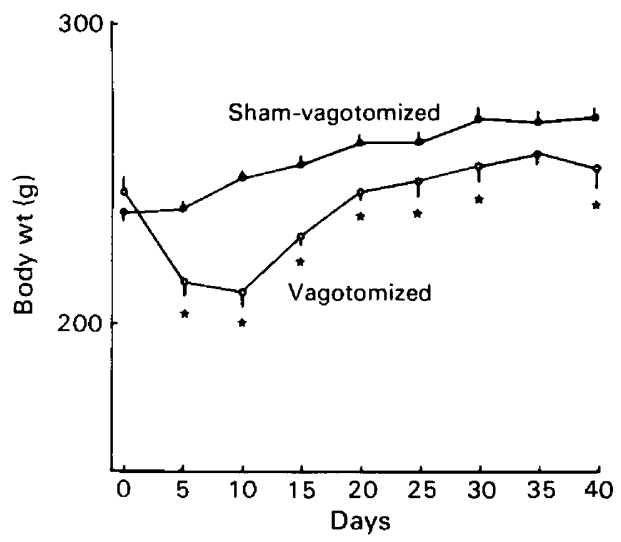

Text-fig. 2. Mean body weights of vagotomized $(O)(N=10)$ and sham vagotomized $(O)$ $(\mathrm{N}=10)$ rats after surgery on the day of pro-oestrus. ${ }^{*} P<0.05$ compared with corresponding sham-vagotomy value.

normal oestrous cycles. One vagotomized rat had a cornified vaginal smear on Day 7. Of 7 pair-fed rats, 5 had a vaginal smear typical of oestrus 5-7 days after the initial period of oestrus. Food intake of vagotomized rats was significantly less than that of sham-vagotomized rats throughout the week (Table 1) and weight loss was similar for vagotomized and pair-fed rats after surgery (Table 2).

During the week after surgery, few vagotomized or pair-fed rats exhibited high afternoon levels of LH (Text-fig. 3). One vagotomized rat had high serum LH on the afternoon of Day 6 and was in oestrus on the following day. While only one elevated concentration of $\mathrm{LH}$ was recorded during the week in the pair-fed rats, 5 of the 7 pair-fed rats became oestrous later in the week. Of 9 shamvagotomized rats, 6 had high afternoon LH concentrations 4 or 5 days after surgery. In sham-

Table 1. Food intake (mean \pm s.e.m.) of vagotomized and sham vagotomized female rats on various days after surgery

\begin{tabular}{|c|c|c|c|c|c|c|c|}
\hline \multirow[b]{2}{*}{ Group } & \multicolumn{7}{|c|}{ Food consumption (g/rat/day) } \\
\hline & Day 1 & Day 2 & Day 3 & Day 4 & Day 5 & Day 6 & Day 7 \\
\hline $\begin{array}{l}\text { Vagotomy } \\
\qquad(\mathrm{N}=10)\end{array}$ & $5 \cdot 2 \pm 0 \cdot 8^{*}$ & $4 \cdot 1 \pm 0 \cdot 9^{*}$ & $5 \cdot 5 \pm 0 \cdot 6^{*}$ & $5 \cdot 7 \pm 0.9^{*}$ & $6 \cdot 7 \pm 1 \cdot 4^{*}$ & $8 \cdot 2 \pm 1 \cdot 7^{*}$ & $8 \cdot 1 \pm 1 \cdot 8^{*}$ \\
\hline $\begin{array}{l}\text { Sham vagotomy } \\
\qquad(N=9)\end{array}$ & $7 \cdot 2 \pm 0 \cdot 5$ & $11.9 \pm 0.6$ & $15 \cdot 6 \pm 0 \cdot 6$ & $16 \cdot 6 \pm 0.6$ & $16.4 \pm 0.8$ & $16.2 \pm 0.9$ & $17.8 \pm 0.6$ \\
\hline
\end{tabular}

* Significantly different from corresponding sham-vagotomy value $(P<0.05)$.

Table 2. Body weights, uterine weights and ovarian weights of female rats 7 days after vagotomy, sham vagotomy or pair feeding with vagotomized rats

\begin{tabular}{lccc}
\hline & $\begin{array}{c}\text { Vagotomy } \\
(\mathbf{N}=10)\end{array}$ & $\begin{array}{c}\text { Sham } \\
\text { vagotomy } \\
(\mathbf{N}=9)\end{array}$ & $\begin{array}{c}\text { Pair } \\
\text { feeding } \\
(\mathbf{N}=7)\end{array}$ \\
\hline Initial body weight $(\mathrm{g})$ & $237 \cdot 8 \pm 6 \cdot 5$ & $251 \cdot 7 \pm 6 \cdot 6$ & $247 \cdot 7 \pm 12 \cdot 2$ \\
Final body weight $(\mathrm{g})$ & $203 \cdot 2 \pm 8 \cdot 7^{*}$ & $249 \cdot 8 \pm 6 \cdot 7$ & $210 \cdot 5 \pm 7 \cdot 3^{*}$ \\
Uterine weight $(\mathrm{mg})$ & $243 \cdot 2 \pm 13 \cdot 8^{*}$ & $321 \cdot 6 \pm 12 \cdot 1$ & $254 \cdot 2 \pm 14 \cdot 2^{*}$ \\
Ovarian weight $(\mathrm{mg})$ & $32 \cdot 3 \pm 2 \cdot 3$ & $31 \cdot 1 \pm 1 \cdot 7$ & $27 \cdot 5 \pm 1 \cdot 9$ \\
\hline
\end{tabular}

Values are mean \pm s.e.m.

* Significantly different from sham-vagotomy value $(P<0.05)$. 

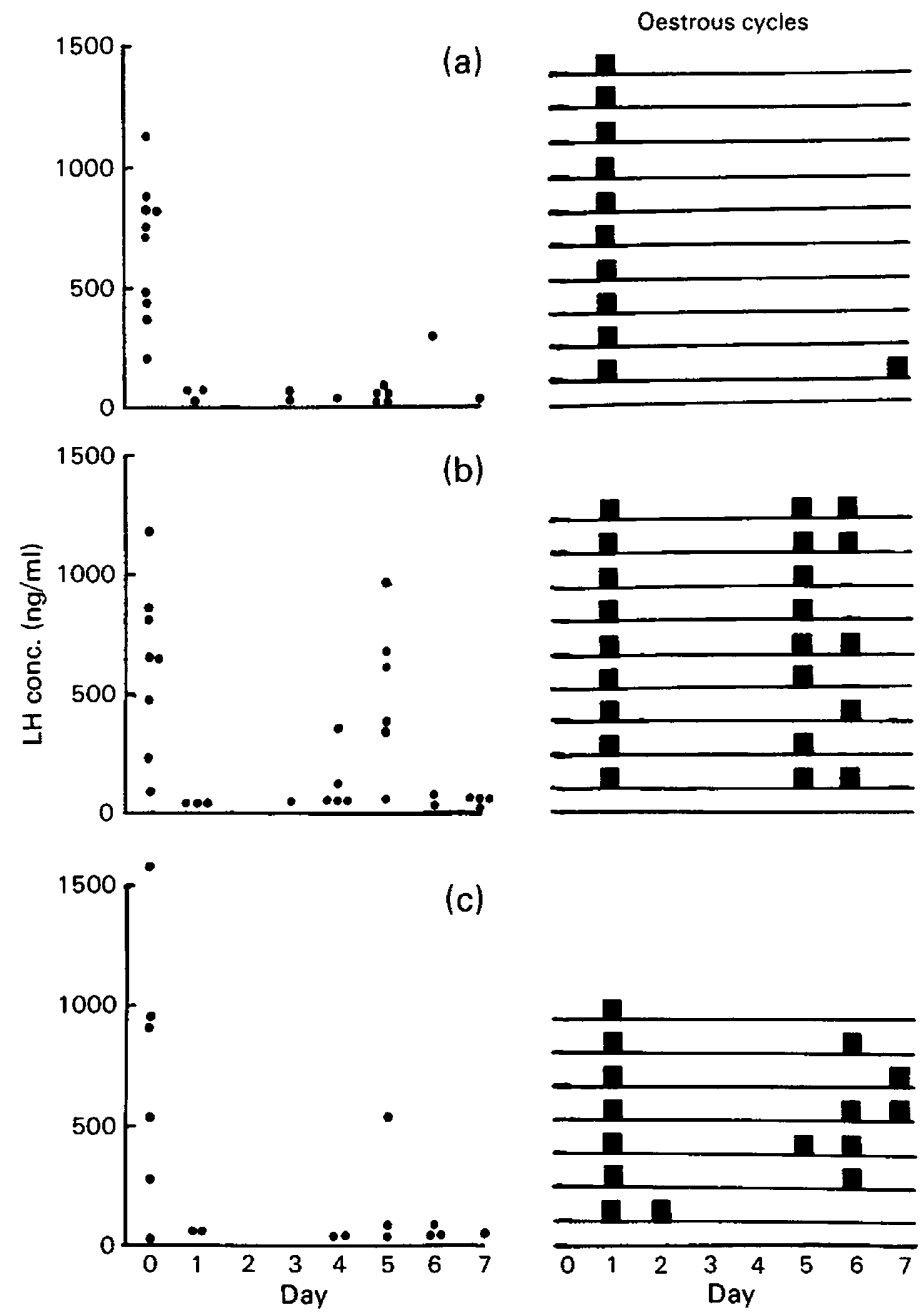

Text-fig. 3. Serum LH and oestrous patterns of vagotomized (a), sham-vagotomized (b) and pair-fed (c) rats. (Pair-fed rats were matched with vagotomized rats, see 'Materials and Methods'.) Surgery was performed on the morning of pro-oestrus (Day 0 ) and rats were bled daily at 16:00 $\mathrm{h}$ from Day 0 to Day 6. Serum LH levels on Day 7 are morning values. Serum LH values are those that were detectable in the assay $(>25 \mathrm{ng} / \mathrm{ml})$. In the oestrous cycle data, symbols represent observation of a cornified vaginal smear.

vagotomized rats having 2 days of cornified vaginal smears, the LH surge occurred on the first day of cornification.

At autopsy, body weights and uterine weights of vagotomized and pair-fed rats were lower $(P<$ $0.05)$ than those of sham-vagotomized rats (Table 2$)$. However, ovarian weights did not differ $(P>$ 0.05 ) between the groups.

Experiment III: steroid-induced LH surges in ovariectomized rats 1 week after vagotomy

LH surges were produced by steroid treatment of ovariectomized rats 7 days after vagotomy or sham vagotomy. Mean \pm s.e.m. serum $\mathrm{LH}$ concentrations $(\mathrm{ng} / \mathrm{ml})$ were not different $(P>0.05)$ between vagotomized and sham-vagotomized rats at 10:00 h (314 \pm 66 and $346 \pm 27$, respectively) $16: 00 \mathrm{~h}(808 \pm 184$ and $843 \pm 97$, respectively $)$ or $18: 00 \mathrm{~h}(381 \pm 84$ and $387 \pm 32$, respectively). 


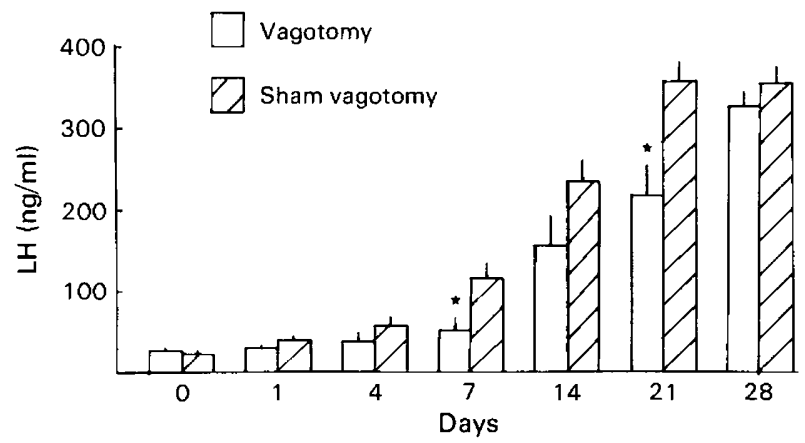

Text-fig. 4. Serum $L H$ concentrations in vagotomized $(N=7)$ and sham-vagotomized $(N=9)$ rats after ovariectomy. Values are mean \pm s.e.m. ${ }^{*} P<0.05$ compared with corresponding sham-vagotomy value.

\section{Experiment IV: effect of vagotomy on the release of $L H$ after ovariectomy}

After ovariectomy at dioestrus, serum LH concentrations increased slowly, as is usual for female rats (Text-fig 4) (Gay \& Midgley, 1969; Yamamoto, Diebel \& Bogdanove, 1970; Zanisi \& Martini, 1975). At 1 and 4 days after surgery, serum LH concentrations were low and there was no difference $(P>0.05)$ between the values for vagotomized and sham-vagotomized rats. At 7 and 21 days after surgery, serum LH concentrations of vagotomized rats were lower $(P<0.05)$ than those of sham vagotomized rats.

\section{Discussion}

Abdominal vagotomy of female rats has been shown to disrupt a number of reproductive functions (Burden \& Lawrence, 1977; Lawrence et al., 1978; Burden et al., 1981; Sanders \& Peppler, 1982; Ojeda et al., 1983). In the present study, vagotomy on the morning of pro-oestrus did not prevent the LH surge at pro-oestrus. After oestrus on the next day, vagotomized rats entered a period of acyclicity (Burden et al., 1981 ; present study). The acyclic period of 20 days in the present study was longer than the acyclic period of 10-12 days previously found after vagotomy on the day of prooestrus (Burden et al., 1981). Other work has shown that the acyclic period after vagotomy was not a pseudopregnant state (Burden, Lawrence, Louis \& Hodson, 1983b).

During the acyclic period after vagotomy, LH surges generally do not occur, and basal LH values are also significantly suppressed (Leonard et al., 1984). Similarly, there is some suppression of post-ovariectomy LH levels at analogous time periods. Still, LH surges could be induced in ovariectomized, vagotomized rats at 7 days after surgery, a time when gonadally intact vagotomized rats are acyclic. It is apparent that the period of acyclicity after vagotomy is characterized by low basal LH concentrations and a general lack of afternoon LH surges.

The period of acyclicity after vagotomy is also a period of suppression of food intake and decreased body weight. Several studies have documented decreased food intake and body weight after vagotomy (Mordes et al., 1977, 1979; Eng, Gold \& Wade, 1979). Vagotomized rats also exhibit decreased gastric acid secretion (Legros \& Griffith, 1969), stomach distension (Shay, Komarov \& Guenstein, 1949; Ellis \& Pryse Davies, 1967; Mordes et al., 1979) and reduced gastric emptying (Shay et al., 1949; Mordes et al., 1979). Restrictions in food intake have been shown to suppress both LH release (Howland, 1971, 1972, 1976) and oestrous cyclicity (Mulinos, Pomerantz, Smelser \& Kurzok, 1939; Werner, 1939; Drill \& Burrill, 1944; Maddock \& Heller, 1947; Piacsek \& Meites, 1967; Nakanishi, Mori \& Nagasawa, 1976). It is possible that decreased body weight may have contributed to the suppression of LH and oestrous cyclicity in the present study. However, if shamoperated rats are pair fed with vagotomized rats, they show continued oestrous cyclicity during the 
week after surgery even though they exhibit few elevated concentrations of $\mathrm{LH}$. There are two possible explanations for these results. First, if food restriction is responsible for the suppressed $\mathrm{LH}$ and acyclicity, vagotomized rats may, in effect, be more food-deprived than pair-fed rats, even though body weight loss was similar in the two groups. This is because stomach emptying of vagotomized rats is delayed (Shay et al., 1949; Mordes et al., 1979). Secondly, although true surge levels of LH were rare in pair-fed rats, perhaps the concentrations of LH present in those rats were high enough to elicit ovulation. Full ovulation has been shown to occur after pro-oestrous LH surges of less than full magnitude (Kalra et al., 1971). The ovaries of vagotomized rats may therefore be less responsive to ovulation induction with available endogenous circulating LH than are ovaries of pair-fed rats. Previous work has shown that, in relation to sham-operated rats, fewer vagotomized rats ovulated in response to exogenous gonadotrophins (Sanders \& Peppler, 1982). Also, ovaries from vagotomized rats respond to exogenous gonadotrophins with an altered steroidogenic profile consisting of increased androgen production and decreased production of oestrogen and progesterone (Ojeda et al., 1983).

In vagotomized rats, therefore, suppressed basal $\mathrm{LH}$ values combined with decreased ovarian responsiveness could result in decreased ovarian steroid output. Decreased ovarian steroids would be a less effective positive-feedback stimulus for LH surges. The present study has shown that the hypothalamus-pituitary unit of vagotomized rats is capable of producing LH surges in response to exogenous steroids and suggests that the steroid milieu of vagotomized rats is not adequate to trigger pro-oestrous LH surges. This study has also shown that oestrous patterns are essentially normal following return of cyclicity after vagotomy.

These studies have focussed on $\mathrm{LH}$ release in vagotomized female rats. Since the vagus nerve relays sensory innervation from the rat ovary (Burden et al., 1983), and there are direct neural connections between brainstem vagal nuclei and hypothalamic centres which regulate LH release (Ricardo \& Koh, 1978), it is possible that sensory input of vagal origin may participate in the modulation of LH release. Although there are indications that $\mathrm{LH}$ release is suppressed by vagotomy (Leonard et al., 1984; present study), interpretation of these results may be complicated by the observations of decreased body weight after vagotomy. It is also possible that the vagus nerve may directly affect ovarian function by modulating sensitivity to gonadotrophins (Sanders \& Peppler, 1982; Ojeda et al., 1983). While the major route of information transfer between the ovary and the hypothalamo-hypophysial unit is hormonal, ovarian nerves, both afferent and efferent, may act to 'fine-tune' the system (Burden, 1978).

We thank Carlton Smith, Sandy Rowland, Marilyn Leonard, Wayne Rhodes and Judson Joyner for technical assistance, Sally McDonnell for word processing; Dr. John T. Clark for helpful criticism of the manuscript; and Dr William Pryor and the staff of the Animal Resource Center for care of the animals. This study was supported by NIH grants HD 06899 (to H.W.B.) and HD 16364-02 (to C.A.H.).

\section{References}

Burden, H.W. (1972) Adrenergic innervation in ovaries of the rat and guinea pig. Am. J. Anat. 133, 455-462.

Burden, H.W. (1978) Neural modulation of ovarian function. TINS 1, 85-86.

Burden, H.W. \& Lawrence, I.E., Jr (1977) The effect of denervation on compensatory ovarian hypertrophy. Neuroendocrinology 23, 368-378.

Burden, H.W., Lawrence, I.E., Jr, Louis, T.M. \& Hodson, C.A. (1981) Effects of abdominal vagotomy on the estrous cycle of the rat and the induction of pseudopregnancy. Neuroendocrinology 33, 218-222.
Burden, H.W., Leonard, M., Smith, C.P. \& Lawrence, I.E., Jr (1983a) The sensory innervation of the ovary: a horseradish peroxidase study in the rat. Anat. Rec. 207, 623-627.

Burden, H.W., Lawrence, I.E., Jr, Louis, T.M. \& Hodson, C.A. (1983b) Abdominal vagotomy does not activate the corpus luteum in rats. Neuroendocrinology 37, 288-290.

Drill, V.A. \& Burrill, M.W. (1944) Effect of thiamin deficiency and controlled inanition on ovarian function. Endocrinology 35, 187-192. 
Ellis, H. \& Pryse Davies, J. (1967) Vagotomy in the rat : a study of its effects on stomach and small intestine. $\mathrm{Br}$. J. exp. Pathol. 48, 135-141.

Eng, R., Gold, R.M. \& Wade, G.N. (1979) Ovariectomyinduced obesity is not prevented by subdiaphragmatic vagotomy in rats. Physiol. Behav. 22, 353-356.

Gay, V.L. \& Midgley, A.R. Jr (1969) Response of the adult rat to orchidectomy and ovariectomy as determined by LH radio immunoassay. Endocrino$\log y$ 84, 1359-1364.

Howland, B.E. (1971) Gonadotrophin levels in female rats subjected to restricted feed intake. J. Reprod. Fert. 27, 467-470.

Howland, B.E. (1972) Effect of restricted feed intake on LH levels in female rats. J. Anim. Sci. 34, 445-447.

Howland, B.E. (1976) Gonadotrophin release induced by $\mathrm{GnRH}$ or progesterone in female rats maintained on high or low doses of feed intake. J. Reprod. Fert. 47, 137-139.

Jacobowitz, D. \& Wallach, E.E. (1967) Histochemical and chemical studies of the autonomic innervation of the ovary. Endocrinology 81, 1132-1139.

Kalra, S.P., Ajika, K., Krulich, L., Fawcett, C.P., Quijada, M. \& McCann, S.M. (1971) Effects of hypothalamic and preoptic electrochemical stimulation on gonadotropin and prolactin release in proestrus rats. Endocrinology 88, 1150-1158.

Kalra, P.S., Kalra, S.P., Krulich, L., Fawcett, C.P. \& McCann, S.M. (1972) Involvement of norepinephrine in transmission of the stimulatory influence of progesterone on gonadotropin release. Endocriology 90, 1168-1176.

Lawrence, I.E., Jr \& Burden, H.W. (1976) The autonomic innervation of the interstitial gland of the rat during pregnancy. Am. J. Anat. 147, 81-94.

Lawrence, I.E., Jr, Burden, H.W. \& Louis, T.M. (1978) Effects of abdominal vagotomy of the pregnant rat on L.H and progesterone concentration and fetal resorption. J. Reprod. Fert. 53, 131-136.

Legros, G. \& Grifith, C.A. (1969) The abdominal vagal system in rats. J. Surg. Res. 9, 183-186.

Leonard, M.J., Smith, C.P., Hodson, C.A., Louis, T.M., Lawrence, I.E., Jr, Allen, L.G. \& Burden, H.W. (1984) The effect of vagotomy on ovarian follicular development. Anat. Rec. 208, 471-472, Abstr.

Maddock, W.O. \& Heller, C.G. (1947) Dichotomy between hypophyseal content and amount of circulating gonadotropins during starvation. Proc. Soc. exp. Biol. Med. 66, 595-598.
Mordes, J.P., Herrera, M.G. \& Silen, W. (1977) Decreased weight gain and food intake in vagotomized rats. Proc. Soc. exp. Biol. Med. 156, 257-260.

Mordes, J.P., el Lozy, M., Herrera, G. \& Silen, W. (1979) Effects of vagotomy with and without pyloroplasty on weight and food intake in rats. Am. J. Physiol. 236, R61-R66.

Mulinos, M.G., Pomerantz, L., Smelser, J. \& Kurzok, R. (1939) Estrus-inhibiting effects of inanition. Proc. Soc. exp. Biol. Med. 40, 79-83.

Nakanishi, T., Mori, J. \& Nagasawa, H. (1976) Recovery of pituitary secretion of gonadotrophins and prolactin during re-feeding after chronic restricted feeding in female rats. J. Endocr. 69, 329-339.

Ojeda, S.R., Smith-White, S., Aguado, L.I., Advis, J.P. \& Andersen, J.M. (1983) Abdominal vagotomy delays the onset of puberty and inhibits ovarian function in the female rat. Neuroendocrinology 36, 261-267.

Piacsek, B.E. \& Meites, J. (1967) Reinitiation of gonadotropin release in underfed rats by constant light or epinephrine. Endocrinology, 81, 535-541.

Ricardo, J.A. \& Koh, E.T. (1978) Anatomical evidence of direct projections from the nucleus of the solitary tract to the hypothalamus, amygdala and other forebrain structures in rat. Brain Res. 153, 1-26.

Sanders, T. \& Peppler, R.D. (1982) Effect of subdiaphragmatic vagotomy on ovarian function in cycling and hemicastrate rats. Anat. Rec. 204, 402, Abstr.

Shay, H., Komarov, S.A. \& Guenstein, M. (1949) Effects of vagotomy in the rat. Archs Surg. 59, 210-226.

Stefenson, A., Owman, C., Sjoberg, N.O., Sporrong, B. \& Walles, B. (1981) Comparative study of the autonomic innervation of the mammalian ovary, with particular regard to the follicular system. Cell Tissue Res. 215, 47-62.

Unsicker, K. (1974) Qualitative and quantitative studies on the innervation of the corpus luteum of rat and pig. Cell Tissue Res. 152, 513-523.

Werner, S.C. (1939) Failure of gonadotropin function of the rat hypophysis during chronic inanition. Proc. Soc. exp. Biol. Med. 41, 101-105.

Yamamoto, M., Diebel, N.D. \& Bogdanove, E.M. (1970) Analysis of initial and delayed effects of orchidectomy and ovariectomy on pituitary and serum LH levels in adult and immature rats. Endocrinology 86, 1102-1111.

Zanisi, M. \& Martini, L. (1975) Differential effects of castration on LH and FSH secretion in male and female rats. Acta endocr., Copenh. 78, 683-688. 